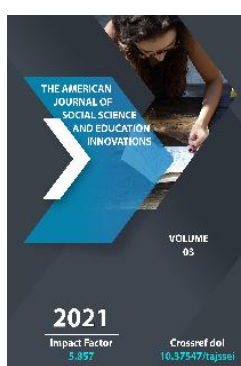

\section{The Teacher's Role In Developing A Sense Of Respect For Socio-Legal Norms In Primary School Children}

Maryambibi Djumaniyazovna Abdullaeva Lecturer Of Department "Preschool Education", Chirchik State Pedagogical Institute, Tashkent Region, Uzbekistan

Copyright: Original content from this work may be used under the terms of the creative commons attributes 4.0 licence.

\title{
ABSTRACT
}

A person's life takes place directly in society, among those who live in it. The effectiveness of interpersonal relations between members of society directly depends on the content of social relations of the individual. The content of public relations, in turn, is determined by the definition of social and legal norms, the degree of their recognition by society, as well as their compliance in practice. The article analyzes social relations in primary school children.

\section{KEYWORDS}

Interpersonal relations, children, primary school, upbringing, society

\section{INTRODUCTION}

Social and legal norms are formed in accordance with the characteristics that are reflected in them, namely, the denial of individual relationships. Although, however, the essence of social and legal norms is not always perceived equally by members of society. According to observations, in most cases, the essence of social and legal norms has a special knowledge of the legal direction, which can be understood only to a certain 
extent by persons acting in the system of judicial, tax, customs or internal affairs. However, given that in the first years of independence of the Republic of Uzbekistan, the restoration of civil society was set as a social goal, the relevance of social and legal norms, the need for all citizens to be equally aware of their content, will increase even more.

Therefore, familiarization of citizens with the essence of social and legal norms, consistent issuance of information about them is one of the tasks that must be solved at the level of society. Among the subjects that have the power of educational influence in the positive solution of this problem, a special place is occupied by educational institutions.

\section{MATERIALS AND DISCUSSION}

Educational institutions are able to establish simple, as well as productive and professional activities, to inform students about social and legal norms that affect the level of human rights protection, their importance, and the need to comply with them. The existing opportunity will ensure the gradual familiarization of students in educational institutions with the content of social and legal norms.

Even in pre-school educational institutions, there is an opportunity to introduce educators to social and legal norms. The information provided to caregivers in this case should be based on social relations, interpersonal interaction, manifested in their daily lives. That is, the relationship of educators with parents, family members, subjects and educators in the micromuhite to which they belong is revealed by the example of social and legal norms that play a priority role in this process. The educator reveals the essence of social and legal norms on the basis of weighing the attention of educators on the basis of identifying the negative or positive content of the actions organized by them (showing what is good, what is bad, what action is right, what action is wrong).

During primary education, the opportunity to familiarize students of this age with social and legal norms increases even more. Because to a certain extent, the essence of social and legal norms is integrated into the content of such academic disciplines as "reading", "etiquette", "the world around us" and "The Constitutional Alphabet". So, how is the introduction of primary school students to social and legal norms based on pedagogical sciences carried out? What should the teacher, who is undoubtedly the main subject in this process, pay attention to when organizing activities? Below we will focus on finding answers to these questions? 


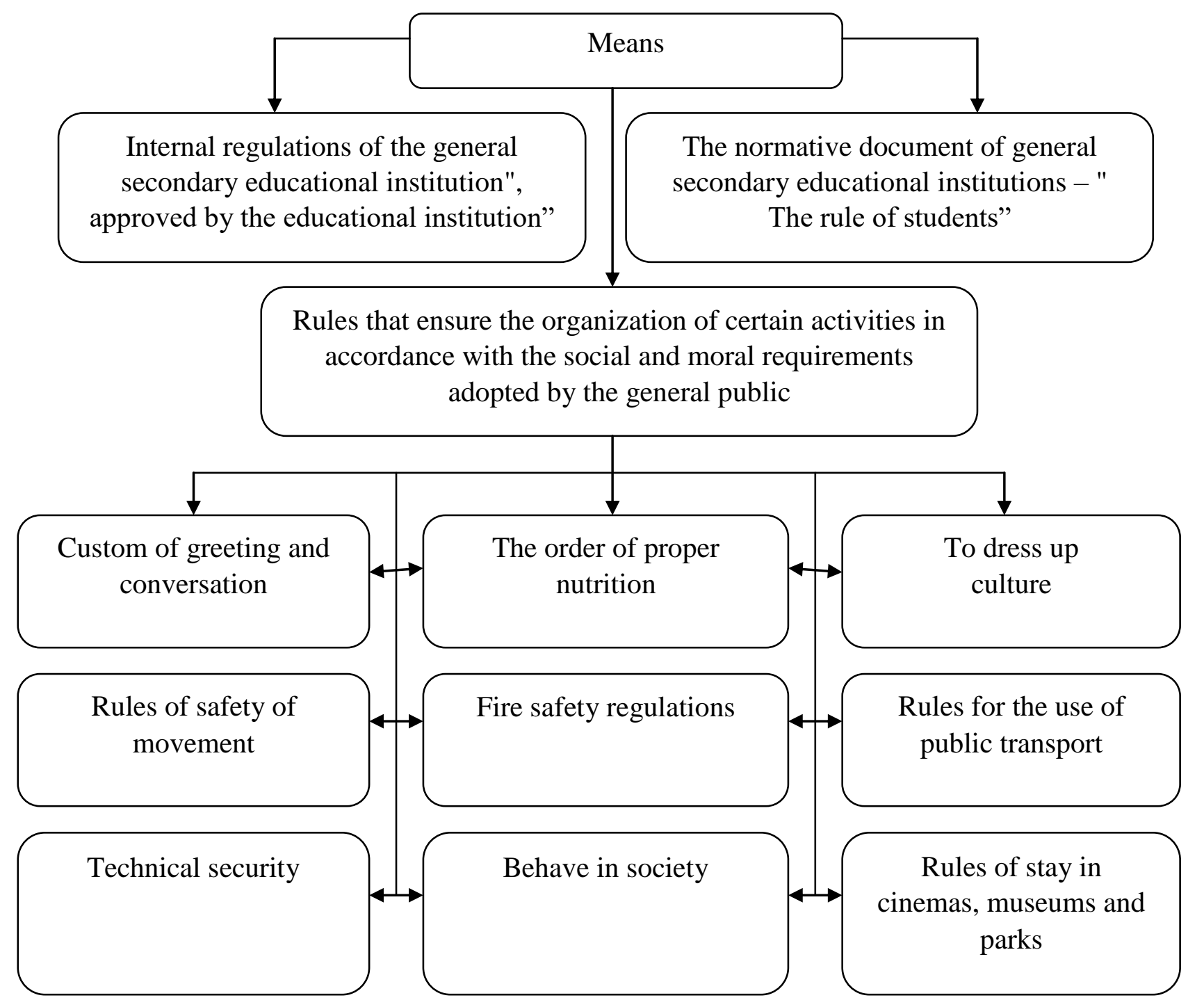

\section{1-Fig. Means of forming a sense of respect for social and legal norms in primary schoolchildren.}

From the point of view of professional activity, the teacher performs the task of teaching children (closer acquaintance with the environment, teaching them to read and write) and education (formation in the reader's personality of moral, intellectual, physical, labor, aesthetic, etc. Even with the formation of a sense of respect for social and legal norms in younger students, the teacher's activity will consist of two important areas, namely: education and upbringing. The main goal of this process is to foster a sense of respect in the minds of students by assimilating theoretical knowledge about social and legal norms, their social and private significance for each individual, and to achieve this goal, the teacher must perform certain tasks. 
Including:

- Distinguish between social norms relevant to the daily activities of primary school children;;

- Analyze the level of complexity of the concepts of separate social and legal norms;

- Assessment of the ability of primary school students to adopt social and legal norms;

- To identify ways, factors, effective forms, methods and means by which the concepts of social and legal norms can be scrupulously mastered by primary school students;;

- Be able to choose advanced pedagogical technologies in order to arouse the interest of younger students in the adoption of social and legal norms;;

- Create the necessary conditions that will allow students to develop skills and competencies for organizing activities in accordance with social and legal norms;

- Identify the difficulties that arise in the process of mastering the knowledge, skills and competencies of primary school children in accordance with social and legal norms, and assign measures to eliminate them;;

- To find a solution to the problem of integrating education and spiritual and educational work in such a way that students can practice their theoretical knowledge about social and legal norms, their essence, social significance, and personal orientation;;

- Monitoring and evaluation of the assimilation by primary school students of knowledge, skills and abilities related to social and legal norms.
RESULTS

Since the teacher organizes pedagogical activities in order to form a sense of respect for social and legal norms in younger students, it is required that he / she be well aware of the sources and means that provide information about social norms. Taking into account the theoretical study of the chosen problem, the age and psychological characteristics of younger students, the possibilities of cognition, it was determined that the teacher should know the following tools that will contribute to the effective assimilation of social and legal norms by younger students (Fig. 1).

Primary school teachers, both the science teacher and the class teacher, contribute to the education of students in a spirit of respect for social and legal norms. The teacher's leadership in a particular class makes it possible to consistently organize activities related to the promotion of social and legal norms not only in the process of education, but also in the course of spiritual and educational work. As a rule, spiritual and educational work is carried out according to the plan. Therefore, the place of activity associated with the promotion of social and legal norms, in terms of spiritual and educational work, increases the effectiveness of pedagogical activity. Plan spirituallyeducational work it is desirable to introduce activities to familiarize students with the rules of" students", etiquette, greetings, order the right food, culture, dressing, rules of human behavior in public areas, safety rules of movement, the terms of use collective clothing, rules of visiting cultural institutions.

The process of primary education, which includes a four-year period, is conditionally 
divided into two stages, according to which students develop cognitive activity, worldview and the ability to think. These two stages should also be taken into account when forming a sense of respect for social and legal norms in primary school children.

In the first and second grades of general education schools in general, students will be able to enrich, strengthen the awareness of their knowledge about social and legal norms in the family and preschool institutions with new concepts that are not as complex as this. At this stage, students will be able to understand the nature of social significance and direction of social norms on the person become familiar with the requirements of the" student rules" of etiquette greetings and conversations, about proper nutrition, as well as the rules of behavior in public places, security, movement, and eating food in public first time or familiarity with the types of established social norms does not cause difficulties in primary school children.

However, while studying in the third and fourth grades of general education schools, students are introduced to social norms, which are somewhat more complex. In particular, they will get acquainted with the rules of dressing up culture, cultural institutions-being in cinemas, museums and parks, fire and technical safety.

\section{Primary education} the two stages listed
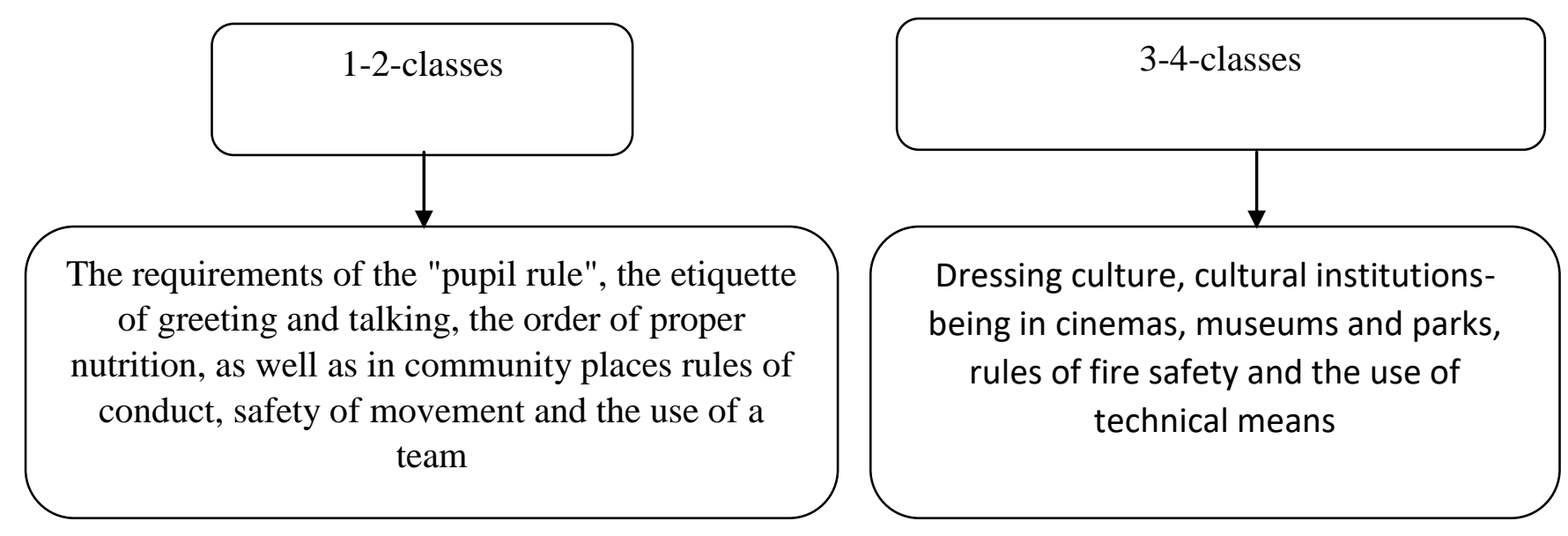

\section{2-Fig. Social and legal norms that are assimilated by students at the two stages of primary education.}

Accordingly, primary school teachers should pay attention to introducing students to social 
above. Effective use of such tools as games, performances with the participation of fairytale characters, illuminating the essence of social and legal norms, fabric fairy tales and puzzles, when explaining the essence of social and legal norms to students of the first and second grades, gives the expected results. Fairy tales and puzzles can be woven directly by the teacher or using samples created by colleagues, writers, and poets.

In the third and fourth grades, the organization of pedagogical activities is carried out on this path in the form of competitions, certain practical tasks. It is also important that the teacher has positive abilities in this process. After all, his creative approach to the organization of educational or spiritual-educational work not only guarantees the achievement of efficiency, but also generates interest in students in relation to the assimilation of social and legal norms.

\section{CONSCLUSION}

Thus, educational institutions have great opportunities to familiarize students with the social and legal norms that constitute the denial of individual relationships. Here, students are gradually introduced to social and legal norms. Educational sciences such as" reading"," etiquette", "the world around us" and" The Constitutional Alphabet " help to introduce students to social and legal norms. Spiritual and educational work carried out in classroom and extracurricular settings ensures consistent organization of the promotion of social and legal norms among students. This means that it is necessary to include in the plan of spiritual and educational work activities that cover the promotion of social and legal norms. In the process of educational and spiritually-educational work of the primary school pupils acquainted with the rules of student conduct, rules, greetings and conversations, the order of proper nutrition, culture, dressing, rules of self-restraint in public areas, safety rules of movement and use of collective clothing, cultural institutions - the movie, rules of stay in public places. Primary school teachers have a special place in the successful organization of these processes. Their creative approaches to the organization and conduct of educational and spiritual-educational activities, along with increasing the effectiveness of pedagogical activities, form students ' interest in the adoption of social and legal norms.

\section{REFERENCES}

1. Abu Ali ibn Sino "Health Secrets" Abdullah Qadiri Publishing House 2000 y.

2. Vohidova N.X. "Fostering national pride in primary school students based on folklore". T-2011

3. Maksadova M.S. Psychological features of the professional training of future primary school teachers. Tashkent-2011

4. Uzakov I. A. "Pedagogical bases of formation of a sense of responsibility in primary school students". Tashkent-2008.

5. Wolff, P. H., Gardner, J., Paccia, J., \& Lappen, J. (1989). The greeting behavior of fragile $X$ males. American Journal on Mental Retardation, 93(4), 406-411 pp. 